\title{
Mechanisms of electrical vasoconstriction
}

\author{
Mark Brinton $^{1 *}$ D, Yossi Mandel ${ }^{2}$, Ira Schachar ${ }^{3}$ and Daniel Palanker ${ }^{3,4}$
}

\begin{abstract}
Background: Electrical vasoconstriction is a promising approach to control blood pressure or restrict bleeding in non-compressible wounds. We explore the neural and non-neural pathways of electrical vasoconstriction in-vivo.

Methods: Charge-balanced, asymmetric pulses were delivered through a pair of metal disc electrodes. Vasoconstriction was assessed by measuring the diameter of rat saphenous vessels stimulated with low-voltage (20 V, $1 \mathrm{~ms})$ and highvoltage $(150 \mathrm{~V}, 10 \mu \mathrm{s})$ stimuli at $10 \mathrm{~Hz}$ for $5 \mathrm{~min}$. Activation pathways were explored by topical application of a specific neural agonist (phenylephrine, alpha-1 receptor), a non-specific agonist $(\mathrm{KCl})$ and neural inhibitors (phenoxybenzamine, $25 \mathrm{mg} / \mathrm{ml}$; guanethidine, $1 \mathrm{mg} / \mathrm{ml}$ ). Acute tissue damage was assessed with a membrane permeability (live-dead) fluorescent assay. The Joule heating in tissue was estimated using COMSOL Multiphysics modeling.

Results: During stimulation, arteries constricted to $41 \pm 8 \%$ and $37 \pm 6 \%$ of their pre-stimulus diameter with low- and high-voltage stimuli, while veins constricted to $80 \pm 18 \%$ and $40 \pm 11 \%$, respectively. In arteries, despite similar extent of constriction, the recovery time was very different: about $30 \mathrm{~s}$ for low-voltage and $10 \mathrm{~min}$ for high-voltage stimuli. Neural inhibitors significantly reduced low-voltage arterial constriction, but did not affect high-voltage arterial or venous constriction, indicating that high-voltage stimuli activate non-neural vasoconstriction pathways. Adrenergic pathways predominantly controlled low-voltage arterial but not venous constriction, which may involve a purinergic pathway. Viability staining confirmed that stimuli were below the electroporation threshold. Modeling indicates that heating of the blood vessels during stimulation $\left(<0.2^{\circ} \mathrm{C}\right)$ is too low to cause vasoconstriction.

Conclusions: We demonstrate that low-voltage stimuli induce reversible vasoconstriction through neural pathways, while high-voltage stimuli activate non-neural pathways, likely in addition to neural stimulation. Different stimuli providing precise control over the extent of arterial and venous constriction as well as relaxation rate could be used to control bleeding, perfusion or blood pressure.

Keywords: Electrical stimulation, Electroceuticals, Vasoconstriction
\end{abstract}

\section{Background}

For decades, electrical stimulation of cardiac striated muscle has been successfully utilized in pacemakers and defibrillators. Recently, electrical control of vascular smooth muscle has been proposed to treat bleeding in non-compressible wounds [1-3]. Understanding the vasoconstriction pathways activated by electrical stimuli will help create safe and effective devices for electrical control of blood vessels.

Constriction of blood vessel involves both neural and non-neural pathways. Non-neural vasoconstriction mechanisms include mechanical stretching (myogenic) $[4,5]$, release of endothelin-1 $[6,7]$ and uridine

\footnotetext{
* Correspondence: brintonmr@gmail.com

${ }^{1}$ Department of Bioengineering, University of Utah, 20 S. 2030 E., Salt Lake

City, UT 84112, USA

Full list of author information is available at the end of the article
}

adenosine tetraphosphate [8] from endothelial cells, circulating hormones (i.e. angiotensin II) $[9,10]$, and damaged platelets [11]. The dominant neural mechanisms include a fast ionotropic (P2X receptor) pathway activated by adenosine triphosphate (ATP) [12-15]; slower metabotropic (alpha-1 and -2 adrenoreceptor) pathways with the release of norepinephrine [15-21]; and the release of neuropeptide $\mathrm{Y}$, which potentiates constriction from norepinephrine and ATP [22-25].

Electrical stimulation of blood vessels has been used to study the neural pathways in constriction [15-18, 26-29] and dilation [30,31], including identification of norepinephrine and ATP involvement by in-vitro stimulation of the rat saphenous artery [13]. Direct electric current induces vasoconstriction and thrombosis [32-34] but also causes tissue damage. In-vitro studies have demonstrated both neural and non-neural electrically induced 
vasoconstriction using a variety of vessel types (pulmonary, somatic and umbilical); however, they used direct or sinusoidal alternating current, which can damage tissue, and could not directly compare the arterial and venous responses to the same stimulation because the vessels were harvested from different locations [28, 29].

Based on our previous studies of vasoconstriction thresholds as a function of pulse duration, frequency, and amplitude [1, 2], we hypothesized that two distinct stimuli ( $20 \mathrm{~V}, 1 \mathrm{~ms}$ and $150 \mathrm{~V}, 10 \mu \mathrm{s}$ pulses at $10 \mathrm{~Hz}$ ) could constrict the rat saphenous artery to a similar extent. Using these stimuli, we sought to compare the extent and recovery time of arterial and venous constriction in-vivo, describe the underlying pathways, and determine whether the stimulation required for vasoconstriction damages the rat saphenous vessels.

\section{Methods}

\section{Animals}

Male, Long Evans rats (Charles River), aged 50-60 days, with average weight of $309 \mathrm{~g}$ (range: 220-380 g) were used in this study with approval by the Stanford Administrative Panel on Laboratory Animal Care. Fourteen animals were used to confirm the maximum constriction using the proposed electrical parameters. In the vasoconstriction and neural inhibition study 7 animals were used for control, 6 for phenoxybenzamine and 5 for guanethidine blockade. Additional five animals were used to assess vessel damage with the live-dead assay. Before surgery, animals were anesthetized using ketamine $\mathrm{HCl}(75 \mathrm{mg} / \mathrm{kg})$ and xylazine $(5 \mathrm{mg} / \mathrm{kg})$, with an additional half dose given every $45 \mathrm{~min}$ thereafter.

For surgery, the animal was placed in the supine position and the rectal temperature was kept at $37 \pm 1{ }^{\circ} \mathrm{C}$. The saphenous artery and vein were exposed by removing the skin. Hartman's Lactated Ringer solution $\left(\sim 37{ }^{\circ} \mathrm{C}\right)$ dripped at about $1 \mathrm{~Hz}$ onto the surgical site during the surgery and stimulation.

\section{Neural inhibitors}

Neural inhibitors were applied topically once the skin was removed and vessels exposed. Phenoxybenzamine $\mathrm{HCl}$ (Sigma Aldrich) was dissolved in DMSO $(25 \mathrm{mg} / \mathrm{ml}$, Sigma Aldrich). Guanethidine monosulfate (MyBioSource) was first dissolved in de-ionized water $(10 \mathrm{mg} / \mathrm{ml})$ and then diluted with DMSO to $1 \mathrm{mg} / \mathrm{ml}$. Control animals $(n=7)$ received DMSO without inhibitors. The solutions were applied liberally $(\sim 200 \mu \mathrm{l})$ to the exposed vessels and covered with a thin piece of plastic to prevent desiccation ( $n=6$ for phenoxybenzamine and $n=5$ for guanethidine). Fresh solution was added $(\sim 200 \mu \mathrm{l})$ about every $5 \mathrm{~min}$ for a total of $25 \mathrm{~min}$. The superficial fascia was removed to improve visualization of the vessel diameters prior to electrical stimulation. Following electrical stimulation, some animals from each group-control (DMSO), phenoxybenzamine and guanethidine-received about $200 \mu \mathrm{l}$ of potassium chloride $(25 \mathrm{mg} / \mathrm{ml}$, Sigma Aldrich; $n=5)$ and, after several minutes of washout, one drop of phenylephrine $\mathrm{HCl}(25 \mathrm{mg} / \mathrm{ml}$, Akorn; $\mathrm{n}=5$ for the Guanethidine block and $n=7$ for the phenoxybenzamine block) as positive controls of vasoconstriction. Potassium chloride acts directly to depolarize nerves and smooth muscle while phenylephrine selectively activates the alpha- 1 adrenergic receptors on smooth muscle cells. Because maximal constriction occurred within several seconds, only the maximal constriction from phenylephrine and potassium chloride are reported.

\section{Vessel stimulation and data collection}

Electrical stimulation and video monitoring of the vessels' width were performed as previously described [2]. Briefly, stainless steel disc electrodes, $1.6 \mathrm{~mm}$ diameter, were placed $3.5 \mathrm{~mm}$ apart, with the saphenous vessels between them. An anodic square pulse from a customized pulse generator was delivered through an $11 \mu \mathrm{F}$ capacitor to the electrodes to assure charge balance. Electrical parameters were selected based on previous studies [1,2], which demonstrated that $150 \mathrm{~V}, 10 \mu$ s stimulation at $1 \mathrm{~Hz}$ induced a maximum constriction (about $30 \%$ of the original diameter), and $20 \mathrm{~V}, 1 \mathrm{~ms}$ stimulation at $1 \mathrm{~Hz}$ produced constriction to $40-45 \%$ of the original diameter. Since constriction also increased with pulse frequency, we hypothesized that $20 \mathrm{~V}, 1 \mathrm{~ms}$ (referred to as low-voltage) and $150 \mathrm{~V}, 10 \mu \mathrm{s}$ (referred to as high-voltage) stimulation, pulsed at $10 \mathrm{~Hz}$, would both reach the state of maximum constriction in the arteries. We first tested these stimulation parameters in 14 animals $(7$ animals with both $20 \mathrm{~V}$ and $150 \mathrm{~V}, 5$ with only $150 \mathrm{~V}$ and 2 with only $20 \mathrm{~V}$ stimuli) without pharmacological treatment (Fig. 1). When multiple stimulations were delivered on the same animal, the second occurred at least $15 \mathrm{~min}$ later and about $1 \mathrm{~cm}$ proximal to first stimulation. Stimulations lasted for $5 \mathrm{~min}$, and the waveforms were monitored using an oscilloscope (Tektronix, TDS 210). The low-voltage stimulus delivered $12.5 \mathrm{~mA}(250 \mu \mathrm{J} / \mathrm{pulse})$ and the high-voltage stimulus $120 \mathrm{~mA}(180 \mu \mathrm{J} / \mathrm{pulse})$, as measured with a $100 \Omega$ series resistor. The inner diameter of blood vessels was measured in Image $(\mathrm{NIH})$ from video captured with a digital camera (Sentech Inc., TC202USB-A).

Data were normalized by the vessel diameter prior to stimulation and presented as mean \pm stdev. Statistical significance $(p<0.01)$ was determined using one-way ANOVA, and, where appropriate, the post hoc Tukey-Kramer test to determine statistical significance between study groups. To compare vessel constriction between study groups, the vessel diameters were averaged over the 5-min stimulation period. 

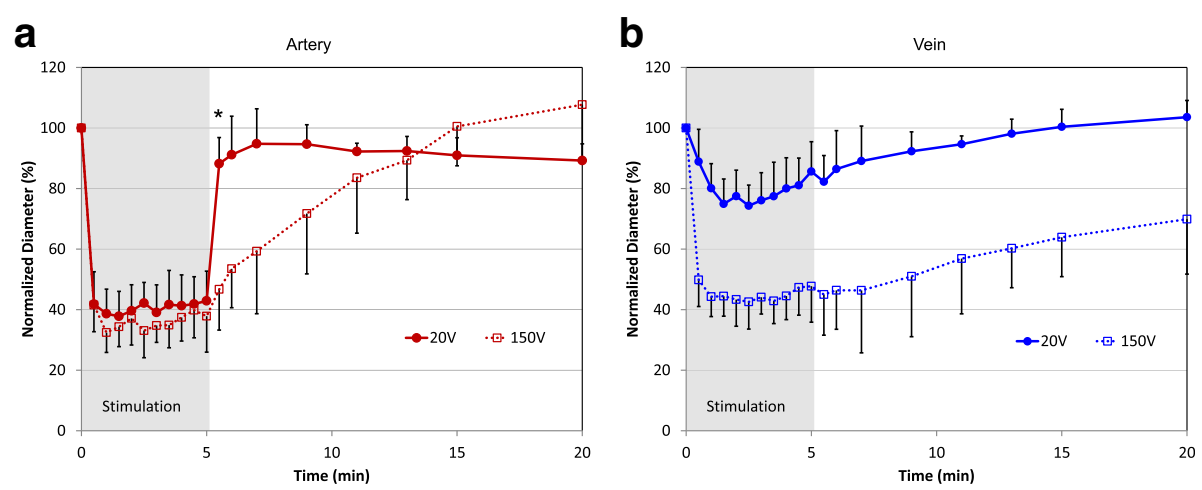

Fig. 1 Arterial and venous constriction in response to $10 \mathrm{~Hz}$ stimulation at $20 \mathrm{~V}, 1 \mathrm{~ms}$ and $150 \mathrm{~V}$, $10 \mu \mathrm{s}$ pulses. a Both stimuli constrict arteries to similar extent, but arteries dilate faster after low-voltage stimulation ( ${ }^{*} p<0.01, \mathrm{~F}(3,34)=23.24$; one-way ANOVA with Tukey-Kramer multicomparison test). $\mathbf{b}$ Veins constrict similarly to arteries at high voltage, but significantly less at low-voltage stimulation $(p<0.01$, $F(3,34)=27.31$; one-way ANOVA with Tukey-Kramer multi-comparison test on the average vessel diameter during stimulation); $N=7$ for $20 \mathrm{~V}$ and $\mathrm{N}=12$ for $150 \mathrm{~V}$ stimuli

\section{Viability staining and vessel damage}

To determine whether the electrical stimulation damaged cell membranes, the saphenous vessels were surgically exposed, as described above, and the femoral artery of anesthetized rats was cannulated with a micro-renethane catheter (Braintree Scientific, MRE-025) [35]. The catheter was advanced to the sapheneous branch, at which time the animal was euthanized. Immediately, the distal end of the saphenous vessel was cut and the vessel flushed with Ringers solution. A viability/cytotoxicity assay (BIOTUM, 30002-T) was pumped through the vessel at a rate of $0.02 \mathrm{ml} / \mathrm{min}$ (New Era Pump Systems, NE-300). While the staining solution flowed through the vessel, electrical pulses ( $20 \mathrm{~V}, 1 \mathrm{~ms} ; 150 \mathrm{~V}, 10 \mu \mathrm{s}$; and $300 \mathrm{~V}, 10 \mu \mathrm{s}$ ) were applied at $10 \mathrm{~Hz}$ for $2 \mathrm{~min}$ to the exposed vessel in ascending order of voltage, moving the electrodes by $5 \mathrm{~mm}$ for each voltage setting, along the saphenous vessels. Stimulation at $300 \mathrm{~V}, 10 \mu$ s was included as a positive control to validate the viability/cytotoxicity assay. After the last stimulation, the assay continued to flow through the vessel for another $15 \mathrm{~min}$. The vessel was then again flushed with Ringers solution, excised and mounted on a glass slide for imaging. The cytotoxicity component of the assay (ethidium homodimer III) only enters the cells with damaged membranes to label the nuclei red, while the viability component (calcein AM) crosses uncompromised cell membranes to label the entire viable cell green. The number of damaged cells (red) for each case were counted using Image and normalized by the control.

\section{Multiphysics modeling}

Based on the electric current measured in-vivo, we modeled the electric field and tissue heating using COMSOL Multiphysics. The model assumed symmetry with respect to the plane passing through the middle of the disk electrodes to reduce the modeling volume to $1.5 \times 0.5 \times$
$0.7 \mathrm{~cm}$. The tissue was assumed to have electrical and thermal properties of a muscle, and a $0.1 \mathrm{~cm}$ thick saline layer covered the $0.6 \mathrm{~cm}$ thick muscle layer. Blood vessels in the muscle layer were modeled as $0.6 \mathrm{~cm}$ long cylinders of blood. Because constricted vessel diameters (especially the vein) depend on the electrical stimulus applied, we modeled the vessel diameters and flow rates according to our previous work (Table 1) [2]. The vessels passed between two $0.16 \mathrm{~cm}$ diameter electrodes, separated by $0.35 \mathrm{~cm}$, center-to-center. Electrodes were placed in direct contact with the muscle tissue, covered with saline.

To model the electric field in the tissue, we applied voltage pulses and chose tissue conductivity so that the total injected current matched the current measured in-vivo (12.5 mA and $120 \mathrm{~mA}$ for the $20 \mathrm{~V}$ and $150 \mathrm{~V}$ stimuli). The in-vivo currents delivered through the electrodes were measured using a $100-\mathrm{Ohm}$ resistor in series with the electrode and tissue. The current was measured at pulse onset, before the capacitive interface had charged.

The electrode surfaces were defined as equipotential, and all other model boundaries were insulating. To calculate the average Joule heating, the power density from one electrical pulse was multiplied by the duty cycle of the pulsed stimulus ( 0.01 for $1 \mathrm{~ms}$ pulses and 0.0001 for $10 \mu$ s pulses). To account for the recharge

Table 1 In-vivo vessel diameters and flow rates used in the COMSOL modeling

\begin{tabular}{lll}
\hline Applied Stimulus & Artery & Vein \\
\hline \multirow{2}{*}{$20 \mathrm{~V}, 1 \mathrm{~ms}$} & Constricted Diameter $(\mu \mathrm{m})$ & \\
$150 \mathrm{~V}, 10 \mathrm{\mu s}$ & 200 & 430 \\
& 160 & 180 \\
$20 \mathrm{~V}, 1 \mathrm{~ms}$ & Flow Rate [2] $(\mathrm{m} / \mathrm{s})$ & \\
$150 \mathrm{~V}, 10$ Hs & 0.15 & 0.12 \\
\hline
\end{tabular}


phase of the pulse, we took the conservative approach and doubled this average power density. In muscle, a perfusion term was included according the bioheat equation [36]. Blood flow rates through the vessels were estimated using the in-vivo measured diameters and published bleeding rates of electrically constricted saphenous vessels in rats of similar weight and electrical parameters (Table 1) [2]. Blood flowed into the model at $37^{\circ} \mathrm{C}$ from the rear in both vessels, a simplification justified by the minimal blood heating due to high flow rates. The boundaries of the modeled volume were set to $37^{\circ}$ $\mathrm{C}$ to reflect body temperature and the drip of the warm saline onto the vessels. The muscle and saline boundaries in the plane of symmetry were insulating. The electrical and thermal material properties are detailed in Table 2. The tissue temperature reached a steady state within about $25 \mathrm{~s}$ of stimulation. For comparison, the tissue heating without blood flow through the vessels was also calculated.

\section{Results}

\section{Electrical stimulation of blood vessels}

Upon electrical stimulation, arteries constricted to $41 \pm 8 \%$ and $37 \pm 6 \%$ of the initial vessel diameter with $20 \mathrm{~V}, 1 \mathrm{~ms}$ and $150 \mathrm{~V}, 10 \mu$ s pulses repeated at $10 \mathrm{~Hz}$ (Fig. 1(a)). While arteries constricted to a similar extent with both stimuli, vessels treated with low-voltage dilated back to $90 \%$ of the initial diameter within $30 \mathrm{~s}$, while vessels treated with high-voltage stimulation recovered after $10 \mathrm{~min}$.

With high-voltage stimulation, veins constricted to a similar extent as arteries $(40 \pm 11 \%$ of the initial vessel diameter), but to only $80 \pm 18 \%$ of the initial diameter with low-voltage stimuli (Fig. 1(b), $p<0.01$ ). Veins also recovered slower than arteries -10 min with low-voltage and $15 \mathrm{~min}$ with high-voltage stimuli.

\section{Assessment of tissue damage by electrical stimulation} To evaluate tissue damage by electrical stimulation (electroporation), we applied a fluorescent cell viability assay to stimulated blood vessels: cells with permeabilized membranes fluoresce in red, while intact cells are stained with green. As shown in Fig. 2, a limited number of damaged cells (red) can be seen in the vessel

Table 2 Electrical and thermal parameters for COMSOL modeling

\begin{tabular}{llll}
\hline & Muscle & Blood & Saline \\
\hline Electrical Conductivity $(\mathrm{S} / \mathrm{m})$ & $0.376(20 \mathrm{~V})[51]$ & $0.76[52,53]$ & 1.0 \\
& $0.475(150 \mathrm{~V})[51]$ & & \\
Thermal Conductivity $(\mathrm{W} / \mathrm{m} \cdot \mathrm{K})$ & $0.52[53]$ & $0.5[54]$ & 0.59 \\
Specific Heat Capacity $(\mathrm{J} / \mathrm{kg} \cdot \mathrm{K})$ & $3550[54]$ & $3840[54]$ & $4173[55]$ \\
Density $\left(\mathrm{kg} / \mathrm{m}^{3}\right)$ & $1041[53]$ & $1055[56]$ & $1000[56]$ \\
Perfusion Parameter $\left(\mathrm{s}^{-1}\right)$ & $0.00067[53]$ & $\mathrm{NA}$ & $\mathrm{NA}$ \\
\hline
\end{tabular}

walls of the control (no stimulation), as well as in the $20 \mathrm{~V}$ and $150 \mathrm{~V}$ samples. However, with the $300 \mathrm{~V}$ stimuli $(10 \mu$ s pulses at $10 \mathrm{~Hz})$, the number of damaged cells increased 4.7 -fold $(p<0.05)$ and the arterial wall dilated beyond its non-stimulated diameter.

\section{Tissue heating by electrical stimulation}

To assess the extent of tissue heating during stimulation, we modeled the system using COMSOL Multiphysics. At steady-state, about $25 \mathrm{~s}$ of stimulation, the temperature on electrode surface increases by about $0.96{ }^{\circ} \mathrm{C}$ with $20 \mathrm{~V}$ and by $0.61{ }^{\circ} \mathrm{C}$ with $150 \mathrm{~V}$ stimuli (Fig. 3). Near blood vessels, the steady-state temperature rise was only $0.2{ }^{\circ} \mathrm{C}$ and $0.15{ }^{\circ} \mathrm{C}$ from the $20 \mathrm{~V}$ and $150 \mathrm{~V}$ stimuli, respectively. As a worst-case scenario, we modeled tissue heating without blood flow in the vessels, which yielded temperature rise of $0.6{ }^{\circ} \mathrm{C}$ and $0.35{ }^{\circ} \mathrm{C}$ at the vessel walls. Both temperatures are well within the range of physiological variations, and less than the temperature change from each drip of warmed saline on the vessel surface.

\section{Neural pathways}

To determine whether neural and non-neural pathways were involved in electrically-induced vasoconstriction, we applied a selective neural agonist (phenylephrine), neural inhibitors (phenoxybenzamine and guanethidine), and a non-specific depolarizing agent (potassium chloride). Phenylephrine is a synthetic analog of norepinephrine that binds and activates the alpha-1 adrenergic receptor. Phenoxybenzamine (PBZ) prevents binding to the alpha-1 and alpha-2 adrenergic receptors on smooth muscle cells. Guanethidine prevents the release of adrenergic (norepinephrine) and purinergic (adenosine triphosphate) neurotransmitters from sympathetic nerves. Potassium chloride $(\mathrm{KCl})$ depolarizes both nerves and smooth muscle cells directly. Since maximal constriction occurred immediately following application, we plot these levels of constrictions as horizontal lines in Fig. 4, for comparison.

\section{Neural inhibition: Arteries}

As expected, phenylephrine induced a strong arterial constriction to $45 \pm 16 \%$ of the initial vessel diameter (Fig. 4, green dash). Pretreatment with PBZ completely blocked arterial constriction with phenylephrine-the vessel constricted to only $96 \pm 5 \%$ of the initial diameter $(p<0.01$; Fig. 4(a) and Fig. 4(c), green solid). Potassium Chloride $(\mathrm{KCl})$ produced the largest arterial constriction, down to $25 \pm 2 \%$ of the initial diameter (Fig. 4, black dash). PBZ slightly reduced the constrictive effect of $\mathrm{KCl}$, presumably by preventing the endogenous norepinephrine, released from depolarized nerves, from binding to the adrenergic receptors (alpha-1 and alpha-2) on the smooth muscle cells; however, $\mathrm{KCl}$ can also act on smooth muscle directly 

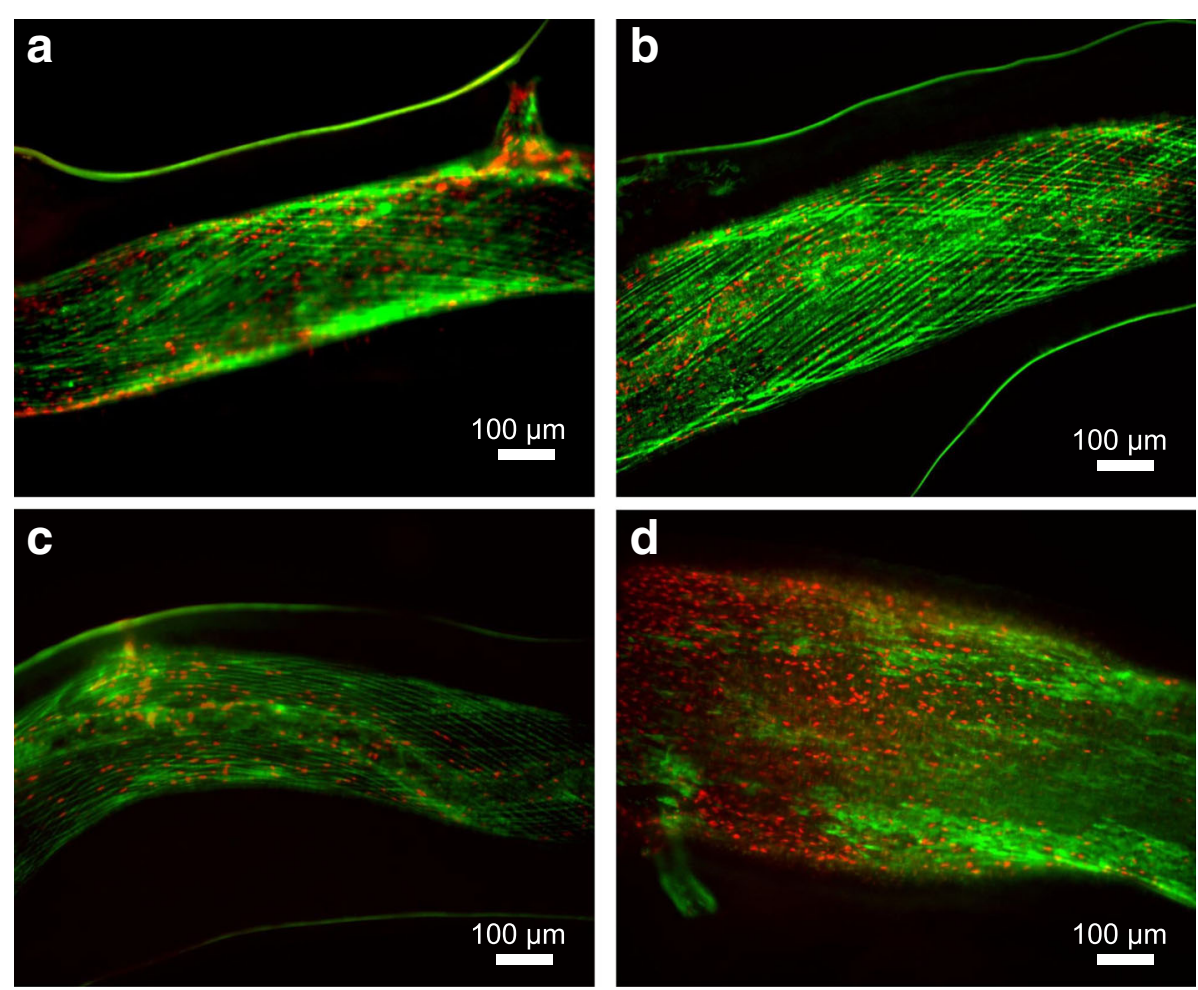

Fig. 2 Cell viability assay of the stimulated artery. Green color indicates intact cells, while red shows cells with compromised cell membrane. a Control with no stimulation ( $N=5)$; b $20 \mathrm{~V}, 1$ ms pulses $(N=5)$; c $150 \mathrm{~V}, 10 \mu$ s pulses $(N=5)$; or $\mathbf{d} 300 \mathrm{~V}, 10 \mu \mathrm{s}$ pulses $(N=4)$. All treatments were applied at $10 \mathrm{~Hz}$ for $2 \mathrm{~min}$. The number of compromised cells was normalized by the control. Vessels stimulated by $20 \mathrm{~V}$ and $150 \mathrm{~V}$ pulses exhibited damage similar to the control $(1.1 \pm 0.8,1.2 \pm 0.3$, and $1.0 \pm 0.6$ a.u., respectively), while the $300 \mathrm{~V}$ stimulation damaged 4.7 -fold more cells ( $4.7 \pm 1.6$ a.u.; $p<0.05$ and $F(3,15)=18.15$, using one-way ANOVA and Tukey-Kramer multi-comparison tests)
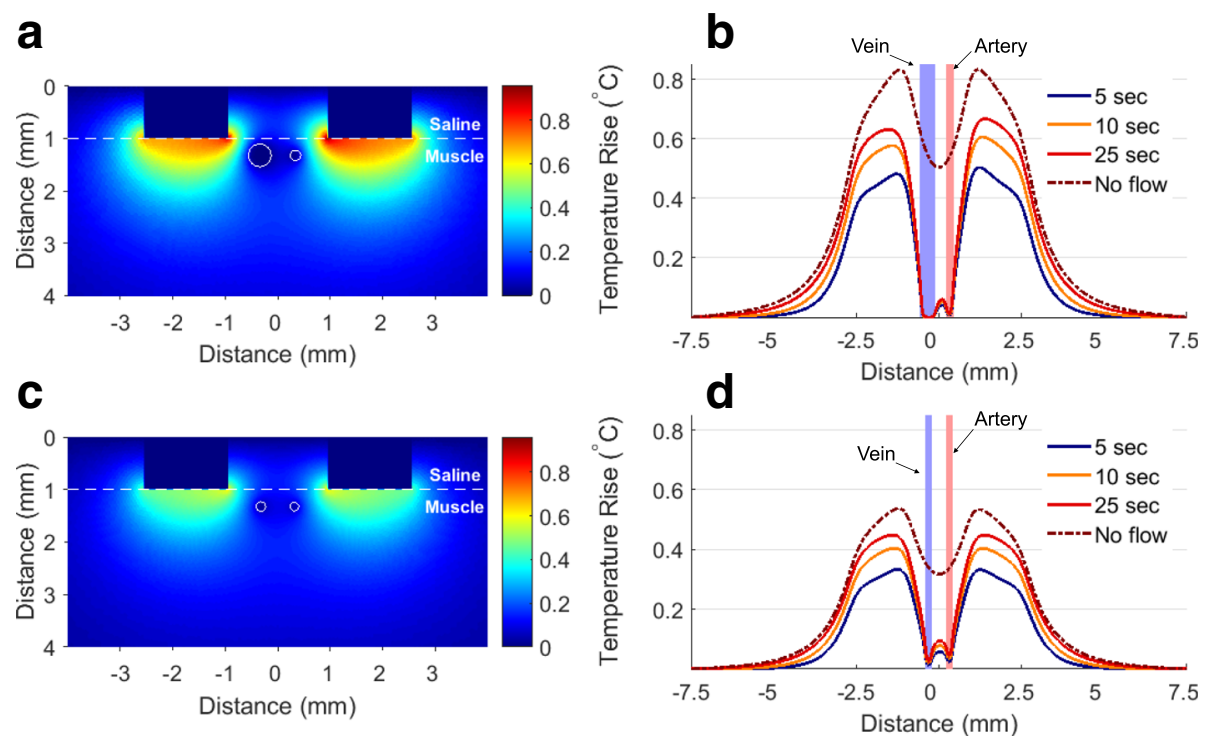

Fig. 3 Temperature rise from a $20 \mathrm{~V}, 1 \mathrm{~ms}$ and c $150 \mathrm{~V}, 10 \mu \mathrm{s}$ stimulations, pulsed at $10 \mathrm{~Hz}$. The temperature rise along the line passing through the center of blood vessels for $\mathbf{b} 20 \mathrm{~V}$ and $\mathbf{d} 150 \mathrm{~V}$ stimulation 

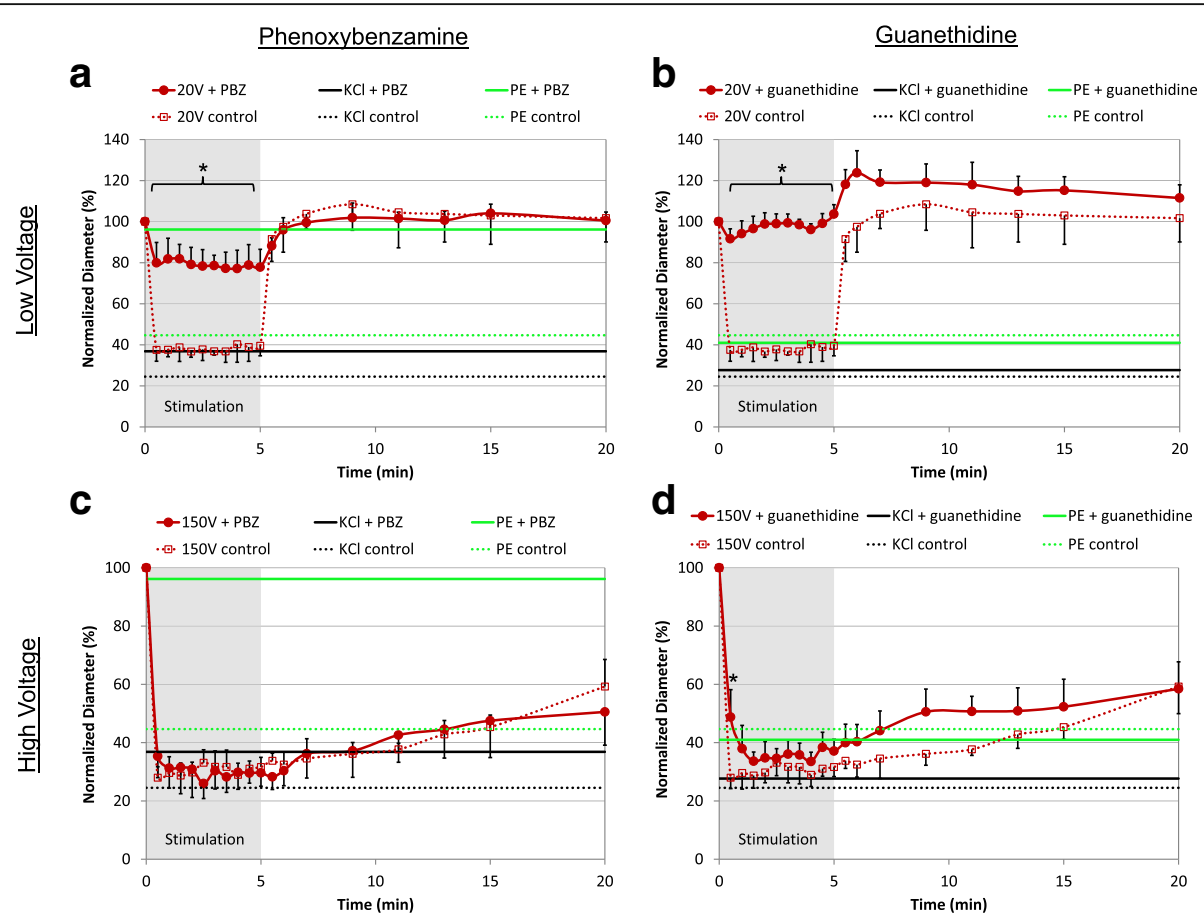

Fig. 4 Neural inhibition of arterial vasoconstriction. a Phenoxybenzamine (PBZ) completely blocked constriction induced by phenylephrine (PE, $p<0.01)$, slightly inhibited constriction induced by potassium chloride $(\mathrm{KCl}, p=0.02)$, and significantly decreased constriction induced by $20 \mathrm{~V}$ stimulation ( ${ }^{*} p<0.01, F(11,58)=98.75$; one-way ANOVA and Tukey-Kramer multi-comparison test). $\mathbf{b}$ Guanethidine had no effect on vasoconstriction induced by PE or by $\mathrm{KCl}$, but it blocked the $20 \mathrm{~V}$-induced constriction $\left({ }^{*} p<0.01\right)$. c PBZ did not inhibit constriction induced by $150 \mathrm{~V}$ stimulation, demonstrating that vasoconstriction by high-voltage bypassed the adrenergic neural pathway. $\mathbf{d}$ On average, guanethidine failed to block constriction induced by $150 \mathrm{~V}$ stimuli. However, the onset of constriction was slowed down $\left({ }^{*} p<0.01\right.$; one-way ANOVA, $\left.F(1,9)=25.14\right)$. Unless specified, significance was determined using one-way ANOVA and Tukey-Kramer multi-comparison test, $F(11,58)=98.75 ; N=5$ for guanethidine, $N=6$ for PBZ and $\mathrm{N}=7$ control. Horizontal lines indicate the maximum constriction achieved with phenylephrine (green) and potassium chloride (black)

so the arterial diameter increased only slightly from $25 \pm 2 \%$ to $37 \pm 4 \%$ of the initial $(p<0.01$; Fig. 4 (a) and Fig. 4(c), black). As expected, Guanethidine failed to inhibit constriction induced by phenylephrine because phenylephrine acts downstream of the guanethidine blockade: $45 \pm 16 \%$ (without guanethidine) compared with $40 \pm 3 \%$ (with guanethidine) of the initial arterial diameter (Fig. 4(b) and Fig. 4(d), green). Guanethidine also had a limited effect on $\mathrm{KCl}$, which can act directly on smooth muscle cells and constricted the vessel to $25 \pm 2 \%$ of the initial vessel diameter without guanethidine, compared with $30 \pm 4 \%$ with guanethidine (Fig. 4(b) and Fig. 4(d), black).

Pretreatment with PBZ reduced arterial constriction with low-voltage $(20 \mathrm{~V})$ stimuli and increased the vessel diameter from $38 \pm 4 \%$ (without PBZ) to $79 \pm 7 \%$ (with PBZ) of the original ( $p<0.01$; Fig. 4(a), red). Pretreatment with guanethidine completely eliminated arterial constriction with low-voltage $(20 \mathrm{~V})$ stimulation-the stimulated vessel diameter increased from $38 \pm 4 \%$ (without guanethidine) to $98 \pm 2 \%$ (with guanethidine) of the pre-stimulus value ( $p<0.01$; Fig. 4(b), red). Guanethidine pretreatment also revealed a post-stimulus dilation up to $127 \%$ of the initial diameter, which trends back to normal over $15 \mathrm{~min}$.
With high-voltage stimulation, PBZ and guanethidine failed to block arterial vasoconstriction: the vessel diameters were $30 \pm 3 \%$ of the initial without PBZ or guanethidine, $30 \pm 6 \%$ with $\mathrm{PBZ}$, and $37 \pm 2 \%$ with guanethidine (Fig. 4(c) and Fig. 4(d), red). However, in the presence of guanethidine, arterial constriction occurred slower: at $30 \mathrm{~s}$ the artery constricted to $28 \pm 4 \%$ of the initial diameter in the control but just $51 \pm 11 \%$ of the initial diameter with guanethidine ( $p<0.01$; Fig. $4(\mathrm{~d})$, red).

\section{Neural inhibition: Veins}

The neural agonists and antagonists affected veins quite differently. Phenylephrine (PE) failed to elicit a venous contraction and was not affected by the neural inhibitors: the vein diameters were $97 \pm 13 \%$ ( $\mathrm{PE}$ alone), $102 \pm 7 \%$ (with PBZ) and $92 \pm 10 \%$ (with guanethidine). PBZ reduced venous constriction with $\mathrm{KCl}$ and increased the vessel diameter from $51 \pm 21 \%$ of the initial to $95 \pm 6 \%$ with PBZ $(p=0.02)$. The increase to $74 \pm 19 \%$ with guanethidine was not significant (Fig. 5, black).

PBZ did not affect the venous response to low-voltage stimulation $(78 \pm 9 \%$ of the pre-stimulus diameter compared with $73 \pm 15 \%$ with PBZ), while guanethidine 

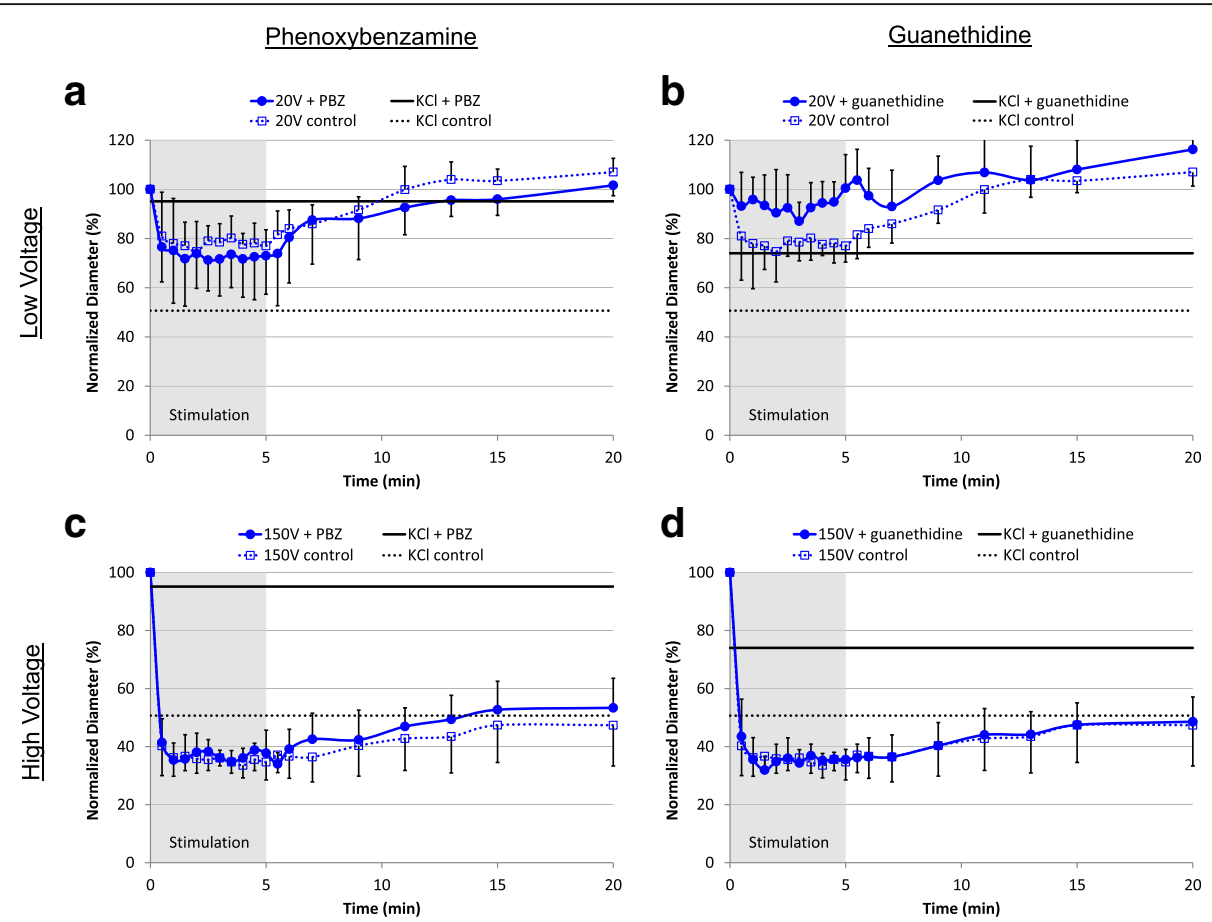

Fig. 5 Neural inhibition of venous vasoconstriction. a PBZ did not block venous constriction induced by $20 \mathrm{~V}$ stimulation, but it reduced constriction induced by $\mathrm{KCl}(\mathrm{p}=0.02)$. b Although guanethidine reduced constriction induced by $20 \mathrm{~V}$ stimulation and by $\mathrm{KCl}$, the differences were not significant. c PBZ did not affect vasoconstriction induced by $150 \mathrm{~V}$ stimulation. d Guanethidine did not affect constriction induced by $150 \mathrm{~V}$ stimulation. Horizontal lines indicate the maximum constriction achieved with potassium chloride (black). Statistical comparisons were performed using the one-way ANOVA and the Tukey-Kramer multi-comparison test; $N=5$ for guanethidine, $N=6$ for PBZ and $N=7$ for control

reduced constriction, but not significantly $(94 \pm 10 \%$ of the pre-stimulus diameter) (Fig. 5(a) and Fig. 5(b), blue). Neither PBZ nor guanethidine affected venous constriction by high-voltage stimulation: vein diameters were $36 \pm 4 \%$ of the pre-stimulus diameter (control), compared with $37 \pm 4 \%$ (PBZ) and $36 \pm 5 \%$ (guanethidine) (Fig. 5(c) and Fig. 5(d), blue).

\section{Discussion}

\section{Electrical stimulation of blood vessels}

We found that both, high- and low-voltage stimuli constrict saphenous arteries to a similar extent in-vivo, but low-voltage engages a neural pathway that recovers quickly (within $30 \mathrm{~s}$ ), while high-voltage activates a non-neural pathway that recovers slowly (over several minutes). We also show that high-voltage stimulation constricts veins as much as arteries, but low-voltage constricts only half that amount. These observations suggest that different vasoconstriction pathways could be activated by electrical stimulation.

\section{Electrical stimulation below damage threshold}

Strong electric field can permeabilize and damage cell membranes; however, our cellular viability assay showed no damage to arteries with the 20 and $150 \mathrm{~V}$ stimuli. Extremely high electric field (tens of $\mathrm{kV} / \mathrm{cm}$ ) with pulse durations shorter than the typical cell polarization time $(\sim 50 \mathrm{~ns})$ can selectively polarize intracellular organelles [37]. While damage of intracellular organelles would not be detected with our viability assay, it is unlikely that our stimulus induced any direct action on them because electric field in our case is about 2 orders of magnitude lower than that required for activation of intracellular organelles. Extremely high electric fields can also activate platelets in the blood, which may constrict vessels by releasing thromboxane or serotonin [11, 38, 39], but this pathway is also unlikely due to the substantially lower electric fields in our study.

With $150 \mathrm{~V}, 0.01 \mathrm{~ms}$ stimuli, charge density at the electrode surface $\left(60 \mu \mathrm{C} / \mathrm{cm}^{2}\right)$ is close to the capacitive coupling limit for stainless steel-electrolyte interface $\left(40-50 \mu \mathrm{C} / \mathrm{cm}^{2}\right)$, and may be delivered without electrolysis due to surface roughness. For the $20 \mathrm{~V}, 1 \mathrm{~ms}$ stimulus, charge density $\left(625 \mu \mathrm{C} / \mathrm{cm}^{2}\right)$ exceeds the capacitive coupling limit, so the current was sustained via electrolysis of water [40]. However, even with electrolysis, it is unlikely that gas byproducts or changes in $\mathrm{pH}$ affected vasoconstriction since the electrodes were located several millimeters away from the vessels and warm saline was continuously washing the tissue surface. To avoid hydrolysis in clinical applications, electrodes should have sufficiently high capacitance, such as sputtered iridium 
oxide films (SIROF), which can safely supply charge densities exceeding $1 \mathrm{mC} / \mathrm{cm}^{2}$ [40].

\section{Heating by electrical stimulation}

For electric field modeling, we selected the muscle conductivity, so that the total current matched the in-vivo measured current $(12.5 \mathrm{~mA}$ or $120 \mathrm{~mA}$ for the 20 or $150 \mathrm{~V}$ electrodes). This approach resulted in a slightly lower value of muscle conductivity for the $20 \mathrm{~V}$ stimulus (likely due to gas formation at the electrode-electrolyte interface). Our thermal modeling demonstrated a temperature rise below $1{ }^{\circ} \mathrm{C}$ on electrodes, and only $0.15-0.2{ }^{\circ} \mathrm{C}$ on the vessel walls, even without considering cooling from convection at the exposed saline surface. Such a minimal heating is very unlikely to induce vasoconstriction since temperature pulsation by a few degrees from a drip of warm saline $\left(37^{\circ} \mathrm{C}\right)$ did not affect the vessel diameter. The vessel heating is similar to our previous reported values (about $2.5{ }^{\circ} \mathrm{C}$ with $150 \mathrm{~V}, 100 \mu$ s pulses at $10 \mathrm{~Hz}$ and $0.02{ }^{\circ} \mathrm{C}$ with $80 \mathrm{~V}, 1 \mu \mathrm{s}$ pulses at $10 \mathrm{~Hz}$ ) [1]; however, our current model predicts even less heating with $150 \mathrm{~V}$ pulses because of about 10-fold less charge per pulse and luminal blood flow based on in-vivo measurements. While variations in blood flow affect the modeling results, even without blood flow, the vessels will heat no more than 0.6 and $0.35^{\circ} \mathrm{C}$ for $20 \mathrm{~V}$ and $150 \mathrm{~V}$ stimuli-again less temperature variation than that produced by the dripping $37^{\circ} \mathrm{C}$ saline.

\section{Neural pathways}

The thermal modeling and cell viability assay suggest that vasoconstriction was not induced by electroporation or vessel heating. To understand the mechanisms of electrical vasoconstriction we applied the pharmacological inhibitors PBZ and guanethidine. PBZ partially blocks neuro-mediated constriction by preventing the neurotransmitter (norepinephrine) from binding to alpha-1 and alpha- 2 receptors on the smooth muscle cells [13], while guanethidine provides a complete neural block by preventing the release of adrenergic (norepinephrine) and purinergic (adenosine triphosphate) neurotransmitters from sympathetic nerves [15].

\section{Neural inhibition during low-voltage stimulation}

In-vivo, low-voltage constriction in arteries was neuro-mediated, with about $65 \%$ of the effect due to the adrenergic pathway and additional $30-35 \%$ from the purinergic pathway, as evidenced by the partial and complete inhibition with PBZ and guanethidine, respectively. Neural vasoconstriction through adrenergic (dominant) and purinergic pathways was also observed ex-vivo in rat saphenous arteries using similar electrical parameters [13]. Low-voltage stimulation did not depolarize the arterial smooth muscle directly in-vivo (evidenced by complete blockage of vasoconstriction with guanethidine) which confirmed ex-vivo observations [13].

PBZ completely eliminated venous constriction by $\mathrm{KCl}$, while it was only slightly reduced in case of arterial constriction by $\mathrm{KCl}$. This implies that $\mathrm{KCl}$ induces venous constriction by depolarizing neurons that release norepinephrine. Because phenylephrine, a pure alpha-1 agonist, did not affect the vein, we conclude that saphenous vein constriction occurs primarily through the alpha- 2 receptors, which are activated by norepinephrine, blocked by PBZ and unaffected by phenylephrine. The alpha- 2 receptor pathway was also shown to be the dominant venous constriction pathway in dogs $[19,20]$. Interestingly, the adrenergic pathway (alpha- 1 and -2 receptors) does not appear to be involved in low-voltage venous constriction because pretreatment with PBZ failed to block constriction. Low-voltage venous constriction may involve activation of a purinergic pathway because veins treated with guanethidine constricted less than without purinergic blockage (Fig. 5(b)).

Low-voltage, neural stimulation primarily affects arterial constriction and flow, which could be useful to control hemorrhage [2], blood perfusion or blood pressure in a localized tissue or organ. The neural pathway provides rapid constriction and dilation and can safely constrict vessels for hours [2]. However, chronic stimulation will require electrode materials capable of safely injecting $625 \mu \mathrm{C} / \mathrm{cm}^{2}$, such as SIROF or TiN $[40,41]$.

Arterial dilation following low-voltage stimulation was observed most clearly in guanethidine treated vessels (Fig. 4(b)), and it may be mediated by release of nitric oxide or prostaglandins [42, 43]. Because the dilation presented only when the neurotransmitters were blocked, the dilatory effect appears to be overpowered under normal stimulation conditions (no pharmacological blockade). Further studies could determine whether this effect could be exploited to increase blood flow in tissue with poor circulation.

\section{Neural inhibition during high-voltage stimulation}

In-vivo, high-voltage vasoconstriction was not dependent on a neural pathway, since it was not affected by neurotransmitter blockers and confirms previous in-vitro studies showing both arterial and venous constriction in the presence of neural inhibitors [28, 29]. Direct depolarization of smooth muscle with high-voltage stimuli is unlikely because high-voltage constriction persists for several minutes after stimulation, unlike $\mathrm{KCl}$-induced constriction which directly depolarizes smooth muscle and reverses within a minute of rinsing the solution. Furthermore, it has been shown that contractility of smooth muscle decreased rapidly below $165 \mu \mathrm{C} / \mathrm{cm}^{2}$ per pulse at $20 \mathrm{~Hz}$ [44]. Our high-voltage stimulation generates 8 -fold less charge density per pulse $\left(20 \mu \mathrm{C} / \mathrm{cm}^{2}\right)$ at the arterial wall with half the 
pulse frequency $(10 \mathrm{~Hz})$, further indicating that a direct effect on smooth muscle is unlikely in our case.

High-voltage electrical vasoconstriction may result from release of endothelin-1 by endothelial cells in the lumen of arteries and veins: endothelin-1 constricts vessels to a similar extent as $\mathrm{KCl}$, and does not readily wash-out (vessels remain constricted for more than $10 \mathrm{~min})[6,7,45,46]$. Endothelial cells under mechanical stress can also release uridine adensosine tetraphosphate and induce potent vasoconstriction [8]. Since vasoconstriction is localized between the electrodes, circulating agents (such as angiotensin) are unlikely to play a role because they would diffuse downstream rather than constrict the vessel only locally.

For some applications, high-voltage, non-neural vasoconstriction has the advantage of constricting veins nearly as much as arteries. This could help control traumatic bleeding in highly perfused tissue, where the major arterial blood supply may be difficult to locate or reach, or in sacral and pelvic cavities where venous hemorrhage can be significant [47-49].

Since high-voltage stimulation uses $40 \%$ less energy per pulse, achieves maximum constriction with 10-fold lower pulse frequency [1], and could be applied intermittently because constriction lasts several minutes, it could enable smaller, more power efficient devices for long lasting vessel control. At $1 \mathrm{~Hz}$, high-voltage delivers 14-fold less power than the low-voltage stimulation.

\section{Limitations}

One limitation of this study is that we have not shown safety for clinically relevant durations of stimulation (i.e. greater than $30 \mathrm{~min}$ ). However, histological examination of the rat saphenous vessels showed no vessel damage one week after a 60-min-long stimulation with identical electrodes at low voltage $(20 \mathrm{~V}, 1 \mathrm{~ms}$ pulses at $10 \mathrm{~Hz})$ [2]. In addition, a previous study demonstrated that the threshold of cellular damage by electroporation does not decrease beyond about 50 pulses, suggesting that longer stimulations should also be safe [50].

The DMSO used in the inhibitor experiments extended the arterial recovery time after high-voltage constriction (comparing Fig. 1(a) and Fig. 4(c)). However, it did not affect the extent of constriction, so comparisons between neural inhibitors and their controls are accurate. Even without DMSO (Fig. 1(b)), the vein did not fully dilate $15 \mathrm{~min}$ after high-voltage stimulation, perhaps due to lower blood pressure compared with the artery.

Electrical stimulation capable of inducing vasoconstriction also activates the nearby muscles and sensory nerves. Due to depletion of acetylcholine at the neuromuscular junction, muscle contraction with each stimulus pulse decreased over time, and was almost gone after about a minute. Unwanted activation of the muscle and sensory nerves could be reduced by using sensors to identify and stimulate only near the source of hemorrhage, by using neuromuscular blocking agents available during general anesthesia or by intermixing the vasoconstriction stimuli with high pulse frequency stimuli, capable of blocking the pain or completely exhausting the neuromuscular junction.

\section{Conclusions}

Pulsed electrical stimulation provides a reversible and non-damaging approach to blood vessel control in-vivo. Low-voltage stimuli engage neural vasoconstriction pathways, while high-voltage also activates non-neural pathways to induce maximum arterial constriction. The low- and high-voltage stimuli provide different extent of constriction and rates of dilation, which could be useful in a variety of applications for control of bleeding, perfusion, or blood pressure.

\section{Abbreviations}

$\mathrm{KCl}$ : Potassium chloride; PBZ: Phenoxybenzamine

\section{Funding}

This work was funded by the U.S. Department of Defense, Air Force Office of Scientific Research (FA9550-14-1-0074).

\section{Availability of data and materials}

The datasets analyzed during the current study are available from the corresponding author on request.

\section{Authors' contributions}

All authors conceived experiments and helped to draft the manuscript. MB performed the experiments and analyzed the data. All authors read and approve the final manuscript

Competing interest

The authors declare that they have no competing interests.

\section{Ethics approval}

This study was approved by the Stanford Administrative Panel on Laboratory Animal Care.

\section{Publisher's Note}

Springer Nature remains neutral with regard to jurisdictional claims in published maps and institutional affiliations.

\section{Author details}

${ }^{1}$ Department of Bioengineering, University of Utah, 20 S. 2030 E., Salt Lake City, UT 84112, USA. Faculty of Life Sciences, Bar Ilan University, 5290002 Ramat-Gan, Israel. ${ }^{3}$ Department of Ophthalmology, Stanford University, 2452 Watson Court Palo Alto, Stanford, CA 94303, USA. ${ }^{4}$ Hansen Experimental Physics Laboratory, Stanford University, 452 Lomita Mall, Stanford, CA 94305, USA.

Received: 12 February 2018 Accepted: 22 May 2018 Published online: 29 May 2018

\section{References}

1. Mandel Y, et al. "Vasoconstriction by electrical stimulation: new approach to control of non-compressible hemorrhage," (in eng). Sci Rep. 2013;3:2111.

2. Brinton MR, Mandel Y, Dalal R, Palanker D. "Miniature electrical stimulator for hemorrhage control," (in eng). IEEE Trans Biomed Eng. 2014;61(6):1765-71.

3. Mandel $Y$, et al. Hemorrhage control of liver injury by short electrical pulses. PLoS One. 2013;8(1):e49852. 
4. Davis MJ, Hill MA. "Signaling mechanisms underlying the vascular myogenic response," (in eng). Physiol Rev. 1999;79(2):387-423.

5. Schubert $R$, Lidington $D$, Bolz SS. "The emerging role of $\mathrm{Ca} 2+$ sensitivity regulation in promoting myogenic vasoconstriction," (in eng). Cardiovasc Res. 2008;77(1):8-18.

6. Furchgott RF, Vanhoutte PM. "Endothelium-derived relaxing and contracting factors," (in eng). FASEB J. 1989;3(9):2007-18.

7. Tykocki NR, Watts SW. "The interdependence of endothelin-1 and calcium: a review," (in eng). Clin Sci (Lond). 2010;119(9):361-72.

8. Jankowski $\mathrm{V}$, et al. "Uridine adenosine tetraphosphate: a novel endotheliumderived vasoconstrictive factor," (in eng). Nat Med. 2005;11(2):223-7.

9. Majumder K, Wu J. "Molecular targets of antihypertensive peptides: understanding the mechanisms of action based on the pathophysiology of hypertension," (in eng). Int J Mol Sci. 2014;16(1):256-83.

10. Zhou Y, Chen Y, Dirksen WP, Morris M, Periasamy M. "AT1b receptor predominantly mediates contractions in major mouse blood vessels," (in eng). Circ Res. 2003;93(11):1089-94.

11. Golino P, et al. "Local platelet activation causes vasoconstriction of large epicardial canine coronary arteries in vivo. Thromboxane A2 and serotonin are possible mediators," (in eng). Circulation. 1989;79(1):154-66.

12. Kur J, Newman EA. "Purinergic control of vascular tone in the retina," (in eng). J Physiol. 2014;592(3):491-504.

13. Tarasova O, Sjöblom-Widfeldt N, Nilsson H. "Transmitter characteristics of cutaneous, renal and skeletal muscle small arteries in the rat," (in eng). Acta Physiol Scand. 2003;177(2):157-66.

14. Burnstock G, Ralevic V. "Purinergic signaling and blood vessels in health and disease," (in eng). Pharmacol Rev. 2014;66(1):102-92.

15. Burnstock $G$, Warland JJ. "A pharmacological study of the rabbit saphenous artery in vitro: a vessel with a large purinergic contractile response to sympathetic nerve stimulation," (in eng). Br J Pharmacol. 1987;90(1):111-20.

16. Sjöblom-Widfeldt N, Nilsson H. "Sympathetic transmission in small mesenteric arteries from the rat: influence of impulse pattern," (in eng). Acta Physiol Scand. 1990;138(4):523-8.

17. Ferrell WR, Khoshbaten A. Responses of blood-vessels in the rabbit knee to electrical-stimulation of the joint capsule. J Physiol. 1990;423:569-78.

18. Khoshbaten A, Ferrell WR. Nerve-mediated responses of blood-vessels in the rabbit knee-joint. J Vasc Res. 1993;30(2):102-7.

19. De Mey J, Vanhoutte PM. "Uneven distribution of postjunctional alpha 1and alpha 2-like adrenoceptors in canine arterial and venous smooth muscle," (in eng). Circ Res. 1981;48(6 Pt 1):875-84.

20. MacLennan SJ, Luong LA, Jasper JR, To ZP, Eglen RM. "Characterization of alpha 2-adrenoceptors mediating contraction of dog saphenous vein: identity with the human alpha 2A subtype," (in eng). Br J Pharmacol. 1997;121(8):1721-9.

21. Dunn WR, McGrath JC, Wilson VG. "Postjunctional alpha-adrenoceptors in the rabbit isolated distal saphenous artery: indirect sensitivity to prazosin of responses to noradrenaline mediated via postjunctional alpha 2adrenoceptors," (in eng). Br J Pharmacol. 1991;103(2):1484-92.

22. Donoso MV, Steiner M, Huidobro-Toro JP. "BIBP 3226, suramin and prazosin identify neuropeptide $Y$, adenosine 5 '-triphosphate and noradrenaline as sympathetic cotransmitters in the rat arterial mesenteric bed," (in eng). J Pharmacol Exp Ther. 1997;282(2):691-8.

23. Cortés $V$, et al. "Synergism between neuropeptide $Y$ and norepinephrine highlights sympathetic cotransmission: studies in rat arterial mesenteric bed with neuropeptide Y, analogs, and BIBP 3226," (in eng). J Pharmacol Exp Ther. 1999:289(3):1313-22.

24. Cheung DW. "Neuropeptide Y Potentiates specifically the purinergic component of the neural responses in the Guinea pig saphenous artery," (in eng). Circ Res. 1991;68(5):1401-7.

25. Fabi F, Argiolas L, Ruvolo G, del Basso P. "Neuropeptide Y-Induced potentiation of noradrenergic vasoconstriction in the human saphenous vein: involvement of endothelium generated thromboxane," (in eng). Br J Pharmacol. 1998:124(1):101-10.

26. Paterson $\mathrm{G}$. "The response to transmural stimulation of isolated arterial strips and its modification by drugs," (in eng). J Pharm Pharmacol. 1965;17:341-9.

27. Yates $\mathrm{CM}$, Gillis $\mathrm{CN}$. "The response of rabbit vascular tissue to electrical and drug stimulation," (in eng). J Pharmacol Exp Ther. 1963;140:52-9.

28. Furchgott RF. "The pharmacology of vascular smooth muscle," (in eng). Pharmacol Rev. 1955;7(2):183-265.

29. Somlyo AV, Somlyo AP. "Electromechanical and pharmacomechanical coupling in vascular smooth muscle," (in eng). J Pharmacol Exp Ther. 1968; 159(1):129-45.
30. Hughes J, Vane JR. Relaxations of isolated portal vein of rabbit induced by nicotine and electrical stimulation. Br J Pharmacol. 1970;39(3):476-89.

31. Torok J, Zemancikova A. Relaxation of rat main pulmonary artery to electrical stimulation: role of nitric oxide. Act Nerv Super Rediviva. 2010;52(2):151-6.

32. Guarini S. A highly reproducible model of arterial thrombosis in rats. J Pharmacol Toxicol Methods. 1996;35(2):101-5.

33. Hladovec J. "Experimental arterial thrombosis in rats with continuous registration," (in eng). Thromb Diath Haemorrh. Oct 1971;26(2):407-10

34. Bourgain RH, F S. A continuous registration method in experimental arterial thrombosis in the rat. Thromb Res. 1974;4:599-607.

35. Jespersen B, Knupp L, Northcott CA. "Femoral arterial and venous catheterization for blood sampling, drug administration and conscious blood pressure and heart rate measurements," (in eng). Vis Exp. 2012;(59). doi: https://doi.org/10.3791/3496.

36. Pennes HH. "Analysis of tissue and arterial blood temperatures in the resting human forearm," (in eng). J Appl Physiol. 1948; 1(2):93-122.

37. Vernier PT, Sun Y, Marcu L, Salemi S, Craft CM, Gundersen MA. "Calcium bursts induced by nanosecond electric pulses," (in eng). Biochem Biophys Res Commun. 2003;310(2):286-95.

38. Torres $A S$, et al. "Platelet activation using electric pulse stimulation: growth factor profile and clinical implications," (in eng). J Trauma Acute Care Surg. 2014:77(3 Suppl 2):S94-S100.

39. Frelinger AL, et al. "Modification of pulsed electric field conditions results in distinct activation profiles of platelet-rich plasma," (in eng). PLoS One. 2016; 11(8):e0160933.

40. Merrill DR, Marom B, GR JJ. Electrical stimulation of excitable tissue: design of efficacious and safe protocols. J Neurosci Methods. 2005;141(2):171-98.

41. Cogan SF. Neural stimulation and recording electrodes. Annu Rev Biomed Eng. 2008;10:275-309.

42. Zhang W, Edvinsson L, Lee TJ. "Mechanism of nicotine-induced relaxation in the porcine basilar artery," (in eng). J Pharmacol Exp Ther. 1998;284(2):790-7.

43. Tartas M, et al. Cathodal current-induced vasodilation to single application and the amplified response to repeated application in humans rely on aspirin-sensitive mechanisms. J Appl Physiol (1985). 2005;99(4):1538-44.

44. van Mastrigt $R$, Glerum JJ. "Electrical stimulation of smooth muscle strips from the urinary bladder of the pig," (in eng). J Biomed Eng. 1985;7(1):2-8.

45. Burnstock G. "Endothelium-derived vasoconstriction by purines and pyrimidines," (in eng). Circ Res. 2008;103(10):1056-7.

46. Yanagisawa $\mathrm{M}$, et al. "A novel potent vasoconstrictor peptide produced by vascular endothelial cells," (in eng). Nature. 1988;332(6163):411-5.

47. Lallemand MS, et al. "Resuscitative endovascular balloon occlusion of the aorta for major abdominal venous injury in a porcine hemorrhagic shock model," (in eng). J Trauma Acute Care Surg. 2017;83(2):230-6.

48. Weber DG, Bendinelli C, Balogh ZJ. "Damage control surgery for abdominal emergencies," (in eng). Br J Surg. 2014;101(1):e109-18.

49. Costantini TW, et al. "Current management of hemorrhage from severe pelvic fractures: results of an American Association for the Surgery of Trauma multi-institutional trial," (in eng). J Trauma Acute Care Surg. 2016; 80(5):717-23; discussion 723-5.

50. Butterwick A, Vankov A, Huie P, Freyvert Y, Palanker D. Tissue damage by pulsed electrical stimulation. IEEE Trans Biomed Eng. 2007;54(12):2261-7.

51. Bronzino JD. The biomedical engineering handbook, 2nd ed. (electrical engineering handbook series). Boca Raton, FL: CRC Press; 2000. p. 2. volumes

52. Duck F. Physical Properties of Tissues: A Comprehensive Reference Book London: Academic Press; 1990

53. Duck FA. Physical properties of tissue : a comprehensive reference book. London: Academic Press; 1990

54. K. Giering, I. Lamprecht, and O. Minet, "Specific heat capacities of human and animal tissues," Proc SPIE 2624, Laser-Tissue Interaction and Tissue Optics, vol. 188, 1996.

55. Fegler G. "Measurement of cardiac output in anaesthetized animals by a thermodilution method," (in eng). Q J Exp Physiol Cogn Med Sci. 1954;39(3):153-64.

56. Christensen DA. Ultrasonic bioinstrumentation. New York: Wiley; 1988. pp. xiii, 235 pages 